\title{
Facilitating the Acquisition of Receptive Vocabulary Knowledge among EFL Undergraduates Using a Cognitive Approach
}

\author{
Abeer Hameed Albashtawi \\ Dr., Luminus Technical University College, Jordan, abeerbashtawil1 @ gmail.com
}

\section{Paramaswari Jaganathan}

Dr., School of Languages, Literacies and Translation, Universiti Sains Malaysia, Malaysia,parames@usm.my

\section{Manjet Kaur Mehar Singh}

Dr., School of Languages, Literacies and Translation, Universiti Sains Malaysia Malaysia,manjeet@usm.my

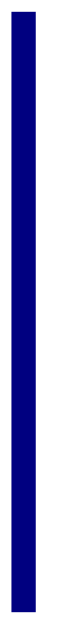

This current quasi-experimental study examined the effect of the Cognitive Academic Language Learning Approach (CALLA) on Jordanian EFL undergraduate RVK- recall and retention. 122 participants took part in this study. Quantitative data were collected by administering a pre, post and delayed vocabulary- reading test. The respondents were assigned as experimental and control groups of English major, at the Hashemite University in Jordan. While CALLA was used as the method of teaching students in the experimental group, the conventional method of teaching students was used in the control group. The analysis of the quantitative data revealed that the RVK of the participants improved in a significant way, where the experimental group outperformed the students in the control group. Furthermore, the delayed post-test proved to be useful in this study as it helped the researcher to capture the long-term learning. Additionally, the analysis of post-delayed test showed that attrition of academic vocabulary occurred in very small amounts. The implications of this study suggest that CALLA could facilitate learning academic language in an effective way which could help students to acquire and remember new vocabulary.

Keywords: academic language, cognitive approach, explicit teaching, receptive vocabulary, strategies

\section{INTRODUCTION}

Learning new words in a second language or a foreign language is a challenging task. New settings propose new demands which necessitate acquiring efficiently specialized

Citation: Albashtawi, A. H., Jaganathan, P., \& Singh, M. K. M. (2020). Facilitating the Acquisition of Receptive Vocabulary Knowledge among EFL Undergraduates Using a Cognitive Approach. International Journal of Instruction, 13(2), 269-284. https://doi.org/10.29333/iji.2020.13219a 
words (Lesaux, Kieffer, Faller, \& Kelley, 2010). For example, vocabulary-learning challenge becomes so great when bringing the issue of academic language that forms the core of different contents in several subject areas in the tertiary classrooms. The bad news is that several teachers do not have a clear idea about teaching vocabulary or even which types of vocabulary should be focused on (Schmitt, 2010). Simultaneously, students entail help and guidance from their teachers who should work as facilitators. Vocabulary absorption during the process of learning all the other skills, such as reading is not an easy task as believed by many (Coady \& Huckin, 1997). While it is helpful to some extent, it is still insufficient, a principled and disciplined approach is needed.

The current education curricula have introduced too much content on the expense of the development of fundamental competencies. Thus, the attention of teachers has been driven on quantity rather than quality. Consequently, frustrated results of students' English language proficiency level continues to be voiced in higher education institutions across the Arab World (Alhabahba, Pandian, \& Mahfoodh, 2016).

Further, the adoption and adaptation of the international curriculum made by the MoE in Jordan without looking at the contextual gaps between the Jordanian/Arab context and western contexts have affected learning in a way that made learning the subject material difficult and further promote rote learning instead of competency development. Jordanian students' needs are varied as new demands are laid on them. Accordingly, conventional methods of teaching have become insufficient to address their new needs as delivering static set of knowledge is not enough. Teachers need to be trained on how to integrate fundamental competencies and learning skills to knowledge (Council, 2017).

Albashtawi, Jaganathan, and Singh (2016), have affirmed in a Jordanian based study, that students' performance in all English skills at the tertiary level is poor and they attributed this poor performance due to the limited acquisition of vocabulary knowledge which is considered as a base for all skills. The inability to reach the desired goals of learning through applying the present teaching methods in Jordan, has led the researchers to try other approaches.

Therefore, the primary goal of the present study was to examine the effectiveness of one of the intervention programs - the Cognitive Academic Language Learning Approach (CALLA) - which could improve the students' RVK recall and retention. CALLA has been applied in L1 and L2 contexts, with inadequate implementation in EFL contexts. The challenge of acquiring academic vocabulary amongst undergraduates can be addressed if the teachers utilize intervention strategies that enhance students' receptive academic vocabularies (Chamot \& O'Malley, 1994).

\section{LITERATURE REVIEW}

The prominent role that vocabulary knowledge plays in foreign language learning and literacy development has been widely researched by several theorists and language learners (Kasper, 1993; Krashen \& Terrell, 1983). Meanwhile Folse (2011, p. 366), stated that "vocabulary is the most crucial component in learning a foreign language", (Krashen, 1989), very early has referred to the distinctive reasons that have proved the importance of paying attention to teaching vocabulary. One among these is that learners 
are in constant need to vocabulary and not to grammar books. Further, studying the acquisition of vocabulary in L2 language contexts would help in understanding the process of acquiring the language. Examples on these are Hunt and Beglar (2005), who asserted the importance of lexicon for language comprehension occurrence. Similarly, Singleton (1999), affirmed that the major challenge of learning and using a language, whether as L1 or L2, lies in the nitty-gritty of the lexicon. Further, Nation (2001) found that the performance of the students with inadequate vocabulary knowledge is generally poorer when compared to students with adequate reservoir of vocabulary in different teaching and learning contexts and that the extent of students' vocabulary knowledge relates strongly to their reading comprehension and overall academic success (Baumann, Kameenui, \& Ash, 2003; Becker, 1977). Likewise, Bromley (2004) in his study on vocabulary development, concluded that vocabulary knowledge improves reading comprehension and fluency, encourages thinking and communicating, and assists in academic achievement.

Considering the Jordanian higher education context, students at the tertiary level who have to learn English as a foreign language are exposed to challenges related to knowing and using vocabulary. These students are learning and using English as it is the medium of instruction in most major courses. Hence, learning new academic concepts, which necessitates knowing and understating academic vocabulary, is inevitable. It is the characteristics of the academic words that make their learning needs more efforts and time when compared to the daily used lexis in the classroom. Academic vocabulary is distinguished by their technicality and frequency of usage (Nation, 2001). Further, academic vocabulary represents the words contained in the academic texts from different academic disciplines. Therefore, learners are hindered from full understanding of the texts due to their short academic vocabulary knowledge. Academic vocabulary is vital for the comprehension to occur (Stahl \& Fairbanks, 1986) in discipline-specific content taught at the tertiary level as it helps in understanding in the academic contexts (Choo, Lin, Singh, \& Ganapathy, 2017). This has drawn researchers' attention that the challenge for students has been in the insufficient academic vocabulary that they have (Evans \& Morrison, 2011).

From a theoretical point of view, the acquisition of ESL/EFL vocabulary shows that vocabulary is acquired in an incremental way and its mastery moves from receptive to productive knowledge (Nation, 2001). In other words, one can increase and expand his knowledge of words over time as learning a word cannot occur based on only one time of exposure. Practically, vocabulary instruction can help and support students' understanding of academic texts. Furthermore, vocabulary instruction should be supported through using scaffolding instruction where students are provided with meaningful and consistent activities and exercises that can improve students' engagement (Bataineh, 2007). However, the agreement on having an effective way to develop students' FL vocabulary is still unclear (Schmitt, 2008).

In a Jordanian based context study, Al-Khasawneh (2013) stated that previous studies on strategy instruction in the Jordanian context showed inconsistent results and they revealed that several of the chosen strategies were ineffective. Therefore, helping 
students to choose the suitable strategies seems to make a sensible goal for instructors to make students independent learners (O'Malley \& Chamot, 1990). Learners' autonomy can be improved by introducing them to different vocabulary learning strategies as well as reading strategies which can be used in developing the learning process. Additionally, vocabulary learning strategies can help students to engage in the learning process and to take more responsibility on their own learning (Martines, 2008). Some studies in L2 contexts reported that it is common to find difficulties among students in the receptive language due to the limited amount of words these students have (Nation, 2001).. These difficulties may lead to gradual loss of motivation and confidence in learning English (Cook, 2001).Thus, an effective instruction to increase the growth of students' vocabulary size is crucial to improve students' academic reading performan.

\section{Teaching of Vocabulary}

Although vocabulary teaching is one of the most important components of any language classroom or English curriculum, the debate for adopting an ideal instructional way of learning and teaching vocabulary continues. One of the issues that have received great attention by researchers is the use of either implicit or explicit approach of teaching vocabulary. It is worthy to note that CALLA instructional framework focuses on the explicit teaching of strategies.

Explicit instruction refers to creating intentional learning conditions (Ellis, 1994), where the learner can acquire the language in a conscious way. An obvious example is when the teacher adapts a clear pattern or works within a framework that should be followed by leaners. However, implicit or indirect method of learning refers to the unconscious way of acquiring information (Ziori \& Dienes, 2012). It refers to the cognitive unobserved interactions that take place to cause learning.

Implicit and explicit methods of teaching vocabulary are two instructional methods that have been widely used in both L1 and L2 contexts. Research showed that promoting implicit learning (indirect teaching) or explicit teaching (direct teaching) of vocabulary instruction depends on several factors. From a theoretical point of view, it should be understood that indirect and direct instructional approaches complement each other. However, there are other methodological or pedagogical reasons that would lead researchers to follow or support one method rather than the other. For example, "teaching interventions are less relevant to implicitly learned skills but essential to explicitly learned ones" (Rebuschat, 2015, p. 1).

Although both implicit and explicit methods of teaching vocabulary are widely employed, Nation (2005) and Lee, Tan, and Pandian (2012) stated that a well-balanced language learning program should combine both direct and indirect instruction. For example, there must be a focus on opportunities to learn from message-focused activities and from direct study of language items. This should be done taking into account that learning with direct study of language items occupies not more than $25 \%$ of the total learning program. Moreover, it has been noticed that the incorporation of direct teaching has been found to be more effective in learning vocabulary than relying on only indirect ways (Folse, 2004; Shintani, 2017). 


\section{The Theoretical Framework of CALLA}

CALLA is based on the cognitive theory which assumes that learners are mentally active participants in the teaching-learning process. CALLA as a complete instructional package focuses on explicit instruction of learning strategies. Learning strategies are defined as mental actions of students which are characterized by the function of using prior knowledge to solve new problems, searching for meaning in receiving information, higher level thinking, and the developing ability to monitor and regulate one's own learning (Chamot, 1995).

This complex process entails extensive practice and feedback to reach the autonomous level. Language proficiency requires not only declarative knowledge, but also procedural knowledge. The use of learning strategies is part of the procedural knowledge. CALLA focuses on the use of procedural skills that facilitate academic language acquisition and content learning (O'Malley, 1988).

\section{CALLA- five recursive phases}

The instructional sequence developed for the Cognitive Academic Language Learning Approach (CALLA) has provided a useful framework for teaching learning strategies. The sequence provides a five-phase recursive cycle for introducing, teaching, practicing, evaluating, and applying learning strategies. In this approach, highly explicit instruction in applying strategies to learning tasks is gradually faded so that the students can begin to assume greater responsibility in selecting and applying their own preferred learning strategies. In the present study, CALLA adapted framework has focused on seven cognitive strategies which included; imagery, sounds, elaboration, making inference, making predictions, paraphrasing, and classifying.

\section{Studies utilized CALLA in EFL contexts}

The review focuses on the studies that have only examined the effect of CALLA and/or strategy explicit instruction on EFL students' receptive vocabulary knowledge. One of the early studies that have employed CALLA is Rasekh and Ranjbary (2003) in which Iranian university students of pre-intermediate level received vocabulary instruction for 10 weeks. They examined the effect of metacognitive vocabulary instruction on lexical knowledge among 53 male and female Iranian EFL students (aged 19 to 25) taking part in an intensive course of English in Tehran Institute of Technology EFL students. The study revealed that teaching metacognitive strategies improved students' vocabulary knowledge. Thus, the study concluded that explicit instruction and training of metacognitive strategies training were successful in improving vocabulary learning of the EFL students. In another similar study, Mizumoto and Takeuchi (2009) investigated the effectiveness of explicit instruction of vocabulary learning strategies within 10 weeks for university Japanese EFL learners. The used instructional framework was CALLA. They concluded that explicit teaching of vocabulary learning strategies improved students' scores in vocabulary test and increased students' use of strategies among the lower and moderate levels of such use. Yet, high level students did not receive that much benefit of the intervention. The study reported that some strategies were found to be time- consuming. Furthermore, CALLA affected students' intrinsic 
motivation. Mizumoto and Takeuchi (2009) revealed that the metacognitive strategies have contributed in the improvement of the students' vocabulary knowledge. They argued that vocabulary training instruction is of great benefit shown through the literature review and the model used proved its usefulness in practicality in teaching metacognitive strategies.

In the Slovenian context, Jurkovic (2010) examined the effect of explicit language learning strategy instruction that was based on CALLA on the development of EFL among students in a university context. The instructional model used in the study included (1) cognitive strategies which were selected to improve participants' language comprehension and production), (2) metacognitive strategies which were chosen to help participants to coordinate, regulate and evaluate their learning process and (3) memory strategies (aiming to facilitate vocabulary retention and recall). The sample included seventy-seven first year students whose ages ranged between 18 and 24. Their major was traffic technology and transport logistics and they were studying English as an FL. Contrary to most studies that have employed CALLA, this study reported that there was no significant effect of explicit language learning strategy instruction on students' learning.

In the Iranian EFL context, Ahari, Sadeghoghli, and Araghi (2014) investigated the significant differences between the levels of proficiency in vocabulary and the use of cognitive, memory, metacognitive and social strategies and those who did not receive the same strategy training. The sample of the study included 50 female first-year students in Tabriz Azad University. The instructional model of CALLA was adapted in this study to develop students and teachers' awareness of learning strategies. The intervention program has been implemented for eight weeks and it focused on teaching students how to use some vocabulary consolidation strategies. Data were collected through pre- and post-questionnaires and were analysed quantitatively. The results showed that there was an increased significance after the instruction in the strategy use and the vocabulary proficiency level.

In two recent Jordanian studies, Al-Khasawneh and Huwari (2014) and Al-Ghazo (2016) examined the effect of the metacognitive strategies on vocabulary learning based on CALLA model. The findings of the two quasi-experimental studies revealed that the experimental groups outperformed the control groups in the vocabulary as a result of the instruction the group received during the intervention time. The findings of their studies showed that the metacognitive strategies proved to be effective. The experimental groups outperformed the control groups in the vocabulary test after the received instruction. Yet, it is worthy to note that the present study is the first one to utilize cognitive strategies based on CALLA model in the EFL Jordanian context. To sum up, although the above-mentioned studies were conducted in different language learning contexts, none of them has focused on the type of language that is investigated. Therefore, a remarkable attention should be given to the type of vocabulary to be investigated. 


\section{METHOD}

The design of this study is a quasi- experimental, where data were collected through quantitative methods of data collection. Quantitative data were collected by administering a pre, post and delayed vocabulary- reading test.

Based on Coxhead academic word list (2000), a compilation of the academic words from the corpus was made by the researchers from the prescribed textbook which was used in the Advanced Reading course. Academic words were compiled by the researcher using Beta text profiler. A total of 30 words (challenge- symbol-enable-vision-images - aware- decline- survive- evolve- generation- enforce- stability-ignore- migrantfederal- displayed-blur -react-survive- intelligence-discrimination-release- uniquedecade-facility- globe- prohibit- isolated-phenomenon-expand) were selected to be taught in the intervention.

\section{Purpose of the Study}

The purpose of this study was to investigate the effectiveness of CALLA on RVK of Jordanian EFL undergraduate students through measuring the RVK recall and retention.

\section{Research Questions}

The following research questions were formulated to investigate the effect of CALLA on RVK of Jordanian EFL undergraduate students:

1. What is the effect of CALLA on RVK recall (short-term retention) of Jordanian EFL undergraduate students?

2. What is the effect of CALLA on RVK retention (retention over time) of Jordanian EFL undergraduate students?

\section{Participants and the Context of the Study}

122 participants were randomly selected from B.A students who registered for the Advanced Reading course at the Department of English and Literature at the Hashemite University in Jordan. Cluster sampling was utilized to carry out random selection of two clusters. The participants were assigned as experimental and control groups. The two groups consisted of 62 and 60 respectively. The Advanced Reading course is a compulsory course for all students at level four, second year. The students' ages ranged between 19-21 years old. They were also homogenous in terms of their mother tongue (which is Arabic), cultural background and the years of studying EFL (12 years) in the Jordanian schools.

\section{Data Collection}

The researcher administered an Academic Reading Test (ART) to collect quantitative data. The academic reading test instrument was constructed by the researcher and consisted of two parts. While part One was constructed to measure students' RVK, part Two was used to measure students' academic reading performance (only part one was used in the current study to answer research questions one and two). Kremmel and 
Schmitt (2016) discussed the issue of testing RVK along with questions (items) on reading comprehension in one single test. The researcher adopted the standardized format of vocabulary and reading tests which commonly includes multiple-choice. The test was validated by a panel consisted of five $\mathrm{PhD}$ holders from two different Jordanian universities. The panel reviewed the test, added and made some comments which were considered by the researchers. Kuder-Richardson 20 (KR-20) for reliability was used to find consistency coefficient, the value reached (0.83) which means that it was a homogenous test.

The intervention lasted for 16 weeks. Meanwhile the third week was assigned to administer the pre-test, weeks 15 and 16 were assigned to administer the post and post delayed test.

\section{Data Analysis}

The research questions were directed toward examining the effect of using CALLA on RVK. A better understanding would be gained through using the Statistical Package for the Social Sciences (SPSS) Version 20 where descriptive statistics such as frequency, mean score and standard deviation were generated as well as inferential statistics such as student $\mathrm{t}$ - test, mixed ANOVA, and one -way ANCOVA.

\section{FINDINGS}

Examining the effect of CALLA on EFL students' receptive vocabulary recall and retention was addressed through analysing students' scores of RVK in academic reading test at pre-test, post-test and delayed test. Table 1 shows the baseline of students' scores for RVK of both control and experimental groups at pre-test stage. As shown in Table 2, the results of Levene's test and t-test revealed that there is no significant difference between the baseline mean scores of the control and the experimental groups (M (SD) = 7.75 (3.250) and 8.74 (3.213), respectively, with t-value $=1.695$, p-value $=0.093)$.

Table 1

Pre-Test mean Scores of Respondents in Control and Experimental Groups

\begin{tabular}{llll}
\hline Group & $\mathrm{N}$ & Mean & SD \\
\hline Experimental & 62 & 8.74 & 3.213 \\
Control & 60 & 7.75 & 3.250 \\
\hline
\end{tabular}

Table 2

Independent Sample T-Test for Scores of Dependent Variables at Pre-Test Levene's test for equality of variances t-test for equality of means

\begin{tabular}{lllllll}
\hline & F & Sig. & t & df & Sig. (2-tailed) \\
\hline & 0.044 & 0.835 & 1.695 & 120 & 0.093 \\
\hline
\end{tabular}

As shown in Table 3, ANCOVA was utilized to obtain the difference between the mean scores in pre- and post-tests while controlling for the pre-test scores as a covariate. Table 3 shows that the RVK mean scores \pm SD of the intervention group (16.56 \pm $2.855)$ are higher than the RVK mean scores \pm SD of the control one (11.55 \pm 3.17$)$. 
Table 3

Mean \pm SD of Intervention and Control Groups at Post-Test

\begin{tabular}{llll}
\hline Group & Mean & Std. Deviation & $\mathrm{N}$ \\
\hline Control & 11.55 & 3.175 & 60 \\
Experiment & 16.56 & 2.855 & 62 \\
Total & 14.10 & 3.919 & 122 \\
\hline
\end{tabular}

As shown in Table 4 below, test of between subject effects clarifies that there is a significant difference between the control and the intervention group in terms of the mean scores of the RVK in the post-test after controlling for the pre-test scores as a covariate $(\mathrm{F}(1,119)=79.70 ; \mathrm{p}$-value $<.001)$.

Table 4

Tests of between-Subject Effects (CALLA and RVK)

\begin{tabular}{llrlll}
\hline Source & \multicolumn{2}{l}{ Type III Sum of Squares df } & Mean SquareF & \multicolumn{2}{l}{ Sig. Partial Eta Squared } \\
\hline Corrected Model & 773.821 & 2 & 386.911 & 42.435 & .000 .416 \\
Intercept & 2890.621 & 1 & 2890.621 & 317.036 .000 .727 \\
rec_vocabul_know_pre 7.094 & 726.677 & 1 & 7.094 & .778 & .380 .006 \\
Group & 1084.998 & 1 & 726.677 & 79.700 & .000 .401 \\
Error & 26108.000 & 1199.118 & & \\
Total & 122 & & \\
Corrected Total & 1858.820 & 121 & & \\
\hline
\end{tabular}

As shown in Table 5, mixed design ANOVA was utilized to determine the differences between the effect of the independent variable (group or the intervention (effect of CALLA) on students' RVK at post-test and delayed post-test compared to their scores at pre-test Table 5 provides the mean scores \pm SD of receptive knowledge mean scores of the intervention and control groups at three points of time (pre-test, post-test and postdelayed test).

Table 5

Mean \pm SD of Control and Intervention Groups at Pre, Post and Post-Delayed RVK Scores

\begin{tabular}{lllll}
\hline & Group & Mean & Std. Deviation & $\mathrm{N}$ \\
\hline rec_vocabul_know_pre & Control & 7.75 & 3.250 & 60 \\
& Experiment & 8.74 & 3.213 & 62 \\
& Total & 8.25 & 3.256 & 122 \\
\hline rec_vocabul_know_post & Control & 11.55 & 3.175 & 60 \\
& Experiment & 16.56 & 2.855 & 62 \\
& Total & 14.10 & 3.919 & 122 \\
\hline rec_vocabul_know_delayed & Control & 10.35 & 3.019 & 60 \\
& Experiment & 15.31 & 2.447 & 62 \\
& Total & 12.87 & 3.695 & 122 \\
\hline
\end{tabular}

As shown in Tables 6 and 7, the main significant effects of time, $F(1.58,189)=166$, pvalue $=.000, \eta p 2=.58$ and group $), F(1,120)=91.993, \mathrm{p}=.000, \eta p 2=.434$. This means that variables other than time or group (study's intervention) are ignored, there will still be significant differences between different time points or control and 
intervention groups. As given in Table 6 below, the changes in receptive knowledge mean scores over different time points are significantly different across the intervention and the control groups.

Table 6

Tests of within-Subject Effects (RVK)

\begin{tabular}{|c|c|c|c|c|c|c|c|}
\hline Source & & $\begin{array}{l}\text { Type III Sum of } \\
\text { Squares }\end{array}$ & $\mathrm{df}$ & $\begin{array}{l}\text { Mean } \\
\text { Square }\end{array}$ & $\mathrm{F}$ & Sig. & $\begin{array}{l}\text { Partial Eta } \\
\text { Squared }\end{array}$ \\
\hline Time & $\begin{array}{l}\text { Greenhouse- } \\
\text { Geisser }\end{array}$ & 2288.052 & 1.578 & 1450.002 & 165.942 & .000 & .580 \\
\hline time * Group & $\begin{array}{l}\text { Greenhouse- } \\
\text { Geisser }\end{array}$ & 324.249 & 1.578 & 205.486 & 23.516 & .000 & .164 \\
\hline Error(time) & $\begin{array}{l}\text { Greenhouse- } \\
\text { Geisser }\end{array}$ & 1654.587 & 189.356 & 8.738 & & & \\
\hline
\end{tabular}

Table 7

Tests of between-Subject Effects (RVK)

\begin{tabular}{lllllll} 
Source & Type III Sum of Squares & df & Mean Square & F & Sig. & $\begin{array}{l}\text { Partial Eta } \\
\text { Squared }\end{array}$ \\
\hline Intercept & 50178.080 & 1 & 50178.080 & 3778.818 & .000 & .969 \\
Group & 1221.555 & 1 & 1221.555 & 91.993 & .000 & .434 \\
Error & 1593.453 & 120 & 13.279 & & &
\end{tabular}

Figure 1 shows pre, post and post-delayed test scores of RVK for the intervention and control groups. The two lines represent the two groups (control and experimental), while the three points on each line represent the three times of measurement (pre-, post, and delayed test). Based on Figure 1, students showed no extreme disparities at pre-test phase which indicates baseline similarity, students performed best at the post-test phase and finally, a slight decrease in their mean scores occurred at delayed-post test phase. 


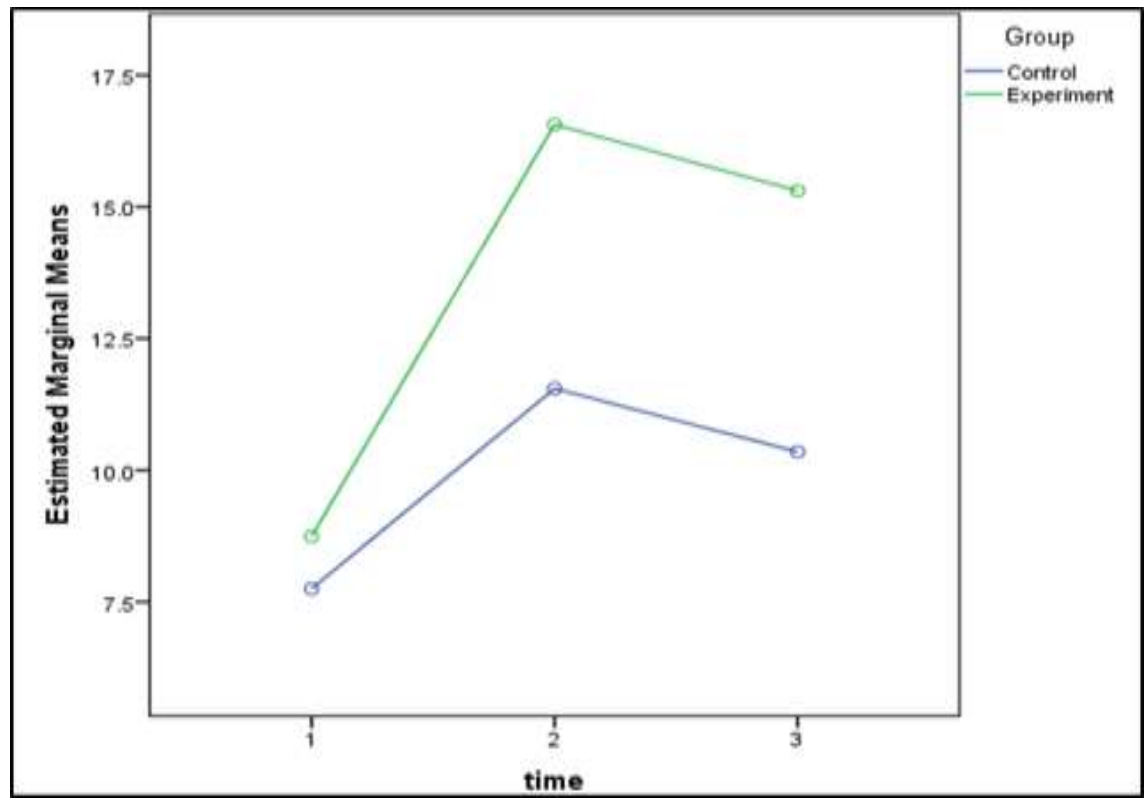

Figure 1

Pre, Post and Post-Delayed Test Scores of RVK for the Intervention and Control Groups

Hence, the overall results indicate that the intervention group performed significantly better than the control group at both post and post-delayed test (RVK recall) mean scores and so null hypothesis is rejected.

\section{DISCUSSION}

The analysis of the quantitative data revealed that the RVK of the participants improved in a significant way. This was obvious because the results showed that after the implementation of CALLA the students in the experimental group outperformed the students in the control group who received instruction in the conventional method. Furthermore, the analysis of post-delayed test showed that attrition of academic vocabulary occurred in very small amounts, because students in the intervention group scored higher than their counterparts in the control group. The improvement in students' RVK reported in this study is consistent with what was reported by Jurkovic (2010) who examined the effect of using CALLA to improve EFL students' vocabulary. These findings are consistent with what has been reported in Ahari et al. (2014) and Mizumoto and Takeuchi (2009) who revealed that students' RVK can be increased through the explicit teaching of cognitive strategies and Rasekh and Ranjbary (2003). Furthermore, this finding supports those reported by Cubukcu (2008) who also reported the positive effect of using CALLA to develop EFL students' vocabulary knowledge. However, Cubukcu (2008), Al-Khasawneh and Huwari (2014) and Al-Ghazo (2016) focused on the metacognitive strategies (which are included in CALLA framework) not the cognitive strategies which were the focus of the current study. 
It is important to note that the reported improvement of RVK among the sample of the current study can be attributed to the effectiveness of CALLA as a good teaching method in which academic words were selected and taught based on what is recommended by CALLA framework. In the current study, form-meaning relationship helped the participants to recognize the different aspects to be focused on while studying words. This, in turn, helped the participants to understand the academic reading texts and to develop their RVK. Although CALLA depends mainly on the explicit instruction of strategies, it cannot be confirmed that incidental learning did not occur during the implementation of CALLA. Students in this study were taught explicitly to use cognitive strategies whereby they could learn through incidental learning. Thus, the conscious processing continues to become unconscious processing after some time.

Furthermore, the results of the analysis of the quantitative data revealed that CALLA improved students' abilities to make inferences, in turn, helped them to improve their abilities in understanding the vocabulary they learnt. Schmitt (2010) and Nation (2001) asserted that inferring meanings from the context and other deep strategies could result in successful retention of vocabulary. These strategies included re-reading the text, guessing the meaning from the context, inferencing the meanings, classifying some different words under one category, paraphrasing and imagery

The results of this study have confirmed that 10 weeks for the real implementation of CALLA was enough to enable the occurrence of the incremental acquisition of vocabulary knowledge (Schmitt, 2010). An immediate post-test was conducted after the treatment to determine its effect on the students' retention of the vocabulary knowledge. This immediate post-test was useful for measuring the effectiveness of CALLA on students' receptive vocabulary and academic reading. Since it has been pointed out that attrition occurs in any learning, a delayed post-test was useful in this study as it helped the researcher to capture the long-term learning. Accordingly, the implementation of CALLA included three sessions: pre, post and delayed post-test. The post-delayed test was conducted two weeks after the second session. The results of the study showed that attrition has occurred but in a very small percentage.

\section{CONCLUSION AND SUGGESTIONS}

The current study was carried out in response to the lack of studies employing effective instructional programs and the lack of studies that examine how vocabulary can be improved. This study focused on the acquisition of vocabulary knowledge. The results of the current study indicated that CALLA as a content-based method of teaching was utilized successfully in the Jordanian EFL context to enhance undergraduates' receptive vocabulary knowledge. Thus, the explicit teaching of instruction assisted students to overcome problems related to recalling and understanding meanings of the words. Therefore, this can reflect that students are capable of transferring these strategies to other contexts where they become independent users of the strategies. CALLA could facilitate learning academic language in an effective way which could help students to acquire new vocabulary.

Furthermore, the present study has come up with some good practical implications that 
can be useful for teaching academic vocabulary explicitly and reading in the Jordanian EFL context and in other similar EFL contexts. The implementation of CALLA successfully could help teachers to design good tasks that encourage students to engage in the classroom after gaining some self-confidence to apply the strategies they have learnt on different exercises. This study could represent a good example on reflecting theory into practice by employing strategy instruction as daily consistent part of CALLA lesson through teacher modelling and guidance would raise the student awareness towards the importance of employing strategies. As a result, the goal shifts from teaching strategies to developing a strategic reader. Such a goal leads to long-term improvements in strategy use and a gradual transfer to independent learning context.

CALLA can also contribute to the body of research which has focused on understanding vocabulary development of undergraduates in Jordan. Further, the findings of this study provide policymakers and educators in the institutions of higher education in Jordan with constructive feedback regarding English language proficiency and teaching academic vocabulary. In the light of the continuous calls for improving students' English proficiency, the current study highlights the importance of considering various approaches that can improve Jordanian EFL students and help them to develop various learning strategies that must be useful for students' future careers.

The findings of the current study and the implementation of CALLA in the Jordanian EFL context have created a good number of issues that deserve researchers' attention. First, an issue that may be considered by future researchers is a replication of the study. The current study examined only the effect of CALLA on RVK (which is an aspect of vocabulary acquisition). Thus, future researchers may consider the effect of CALLA on both receptive and productive vocabulary knowledge together. Although this current study showed the effectiveness of the delayed-test in assessing students' attrition, some researchers have argued that a small number of exposures are unlikely to lead to longterm acquisition of vocabulary. Thus, future researchers may consider examining attrition through either using some other instruments or extending the period of the implementation of CALLA to be for one full year or a longitudinal study that can extend over several years.

\section{REFERENCES}

Ahari, N. H., Sadeghoghli, H., \& Araghi, S. M. (2014). The effect of vocabulary consolidation strategy training on vocabulary learning and vocabulary acquisition consolidation strategy use of intermediate Iranian EFL learners. International Journal of Language and Learning and Applied Linguistics World, 5(3), 40-53.

Al-Ghazo, A. (2016). The effect of explicit instruction of metacognitive learning strategies on promoting Jordanian language learners' reading competence. Journal of Education and Practice, 7(10), 170-177.

Al-Khasawneh, F. M. (2013). The patterns of vocabulary learning strategies employed by EFL learners at Jordan university of science and technology (Unpublished Doctoral Thesis). Universiti Utara Malaysia. 
Al-Khasawneh, F. M., \& Huwari, I. F. (2014). The effect of metacognitive strategies instruction on vocabulary learning among Jordanian university students. International Journal of English and Education, 3(3), 102-113.

Albashtawi, A. H., Jaganathan, P., \& Singh, M. (2016). Linguistic knowledge aspects in academic reading: Challenges and deployed strategies by English-major undergraduates at a Jordanian institution of Higher Education. Higher Education Studies, 6(3), 61-71.

Alhabahba, M. M., Pandian, A., \& Mahfoodh, O. H. A. (2016). English language education in Jordan: Some recent trends and challenges. Cogent Education, 3(1).

Bataineh, R. F. (2007). Perceptions of the impact of the use of English as the predominant medium of instruction on Jordanian economics and administrative science students' academic achievement. Paper presented at the 7th Global Conference on Business and Economics. Rome: Italy.

Baumann, J., Kameenui, E., \& Ash, G. (2003). Research on vocabulary instruction. In J. Flood, D. Lapp, J. R. Squire, \& J. Jensen (Eds.), Handbook of research on teaching the English language arts (pp.752-786). New York: Macmillan.

Becker, W. (1977). Teaching reading and language to the disadvantaged-What we have learned from field research. Harvard Educational Review, 47(4), 518-543.

Bromley, K. (2004). Rethinking vocabulary instruction. Language and Literacy Spectrum, 14, 3-12.

Chamot, A. U. (1995). Implementing the cognitive academic language learning approach: CALLA in Arlington, Virginia. Bilingual Research Journal, 19(3-4), 379394.

Chamot, A. U., \& O'Malley, J. M. (1994). The CALLA handbook: Implementing the cognitive academic language learning approach. Reading, MA: Addison-Wesley Publishing Company

Choo, L. B., Lin, D. T. A., Singh, M. K. M., \& Ganapathy, M. (2017). The significance of the academic word list among ESL tertiary students in a Malaysian public university. 3L: The Southeast Asian Journal of English Language Studies, 23(4), 56-65.

Coady, J., \& Huckin, T. (1997). Second language vocabulary acquisition: A rationale for pedagogy. Cambridge: Cambridge University Press.

Cook, V. J. (2001). Second language learning and language teaching. London: Edward Arnold.

Council, T. B. (2017). The British Council. Retrieved from https://www.britishcouncil.jo/sites/default/files/stem_4.0.pdf.

Cubukcu, F. (2008). Enhancing vocabulary development and reading comprehension through metacognitive strategies. Issues in Educational Research, 18(1), 1-11. 
Ellis, N. C. (1994). Vocabulary acquisition: The implicit ins and outs of explicit cognitive mediation. In N. C. Ellis (Ed.), Implicit and explicit learning of languages (pp. 211-282 ). London: Academic Press.

Evans, S., \& Morrison, B. (2011). Meeting the challenges of English-medium higher education: The first-year experience in Hong Kong. English for Specific Purposes, 30(3), 198-208.

Folse, K. (2011). Applying L2 lexical research findings in ESL teaching. Tesol Quarterly, 45(2), 362-369.

Folse, K. S. (2004). Vocabulary myths: Applying second language research to classroom teaching: University of Michigan Press Ann Arbor, MI.

Freahat, N. M., \& Al-Faoury, O. H. (2014). Jordanian high school EFL teachers' and university EFL instructors' perceptions of the reading comprehension content in EFL textbooks. Theory and Practice in Language Studies, 4(11), 2231-2242.

Hunt, A., \& Beglar, D. (2005). A framework for developing EFL reading vocabulary. Reading in a foreign language, 17(1), 23-59.

Jurkovic, V. (2010). Effect of explicit language learning strategy instruction on language-test and self-assessment scores. English Language Teaching, 3(1), 16-27.

Kasper, L. F. (1993). The keyword method and foreign language vocabulary learning: A rationale for its use. Foreign Language Annals, 26(2), 244-251.

Krashen, S. (1989). We acquire vocabulary and spelling by reading: Additional evidence for the input hypothesis. The modern language journal, 73(4), 440-464.

Krashen, S. D., \& Terrell, T. D. (1983). The natural approach: Language acquisition in the classroom. Alemany Press.

Kremmel, B., \& Schmitt, N. (2016). Interpreting vocabulary test scores: What do various item formats tell us about learners' ability to employ words? Language Assessment Quarterly, 13(4), 377-392.

Lee, B. C., Tan, D. A. L., \& Pandian, A. (2012). Language learning approaches: A review of research on explicit and implicit learning in vocabulary acquisition. ProcediaSocial and Behavioral Sciences, 55, 852-860.

Lesaux, N. K., Kieffer, M. J., Faller, S. E., \& Kelley, J. G. (2010). The effectiveness and ease of implementation of an academic vocabulary intervention for linguistically diverse students in urban middle schools. Reading Research Quarterly, 45(2), 196-228.

Martines, D. (2008). Multicultural school psychology competencies: A practical guide. London: Sage Publications.

Mizumoto, A., \& Takeuchi, O. (2009). Examining the effectiveness of explicit instruction of vocabulary learning strategies with Japanese EFL university students. Language Teaching Research, 13(4), 425-449. 
Nation, I. S. P. (2001). Learning vocabulary in another language. Cambridge: Cambridge Univeristy Press.

Nation, I. S. P. (2005). Second language vocabulary. Cambridge: Cambridge University Press.

O'Malley, J. M. (1988). The cognitive academic language learning approach (CALLA). Journal of Multilingual \& Multicultural Development, 9(1-2), 43-60.

O'Malley, J. M., \& Chamot, A. U. (1990). Learning strategies in second language acquisition. Cambridge: Cambridge University Press.

Rasekh, Z. E., \& Ranjbary, R. (2003). Metacognitive strategy training for vocabulary learning. Tesl-Ej, 7(2), 1-18.

Rebuschat, P. (2015). Implicit and explicit learning of languages (Vol. 48). John Benjamins Publishing Company.

Schmitt, N. (2008). Instructed second language vocabulary learning. Language teaching research, 12(3), 329-363.

Schmitt, N. (2010). Researching vocabulary: A vocabulary research manual. Palgrave Macmillan.

Shintani, N. (2017). The effects of the timing of isolated FFI on the explicit knowledge and written accuracy of learners with different prior knowledge of the linguistic target. Studies in Second Language Acquisition, 39(1), 129-166.

Singleton, D. M. (1999). Exploring the second language mental lexicon. Ernst Klett Sprachen.

Stahl, S. A., \& Fairbanks, M. M. (1986). The effects of vocabulary instruction: A model-based meta-analysis. Review of educational research, 56(1), 72-110.

Ziori, E., \& Dienes, Z. (2012). The time course of implicit and explicit concept learning. Consciousness and Cognition, 21(1), 204-216. 